\title{
Erratum to: Obstructive sleep apnea syndrome is associated with some components of metabolic syndrome in nonobese adults
}

Qi-Chang Lin • Xiao-Bin Zhang • Gong-Ping Chen •

Dou-Yu Huang • Hai-Bo Din • Ai-Zhong Tang

Published online: 27 August 2011

(C) Springer-Verlag 2011

Erratum to: Sleep Breath

DOI 10.1007/s11325-011-0544-7

Footnote line 1: change "X.Zhang and X.-B. Zhang contributed equally to this work" to "QC Lin and X.B Zhang contributed equally to this work"

Footnote line 2-3: change "Q.-C.Lin* X.-B. Zhang* G.-P. Chen* D.-Y. Huang* H.-B. Din* A.-Z. Tang" to "QC Lin* XB. Zhang* GP. Chen* DY. Huang* HB. Din* AZ. Tang"

The online version of the original article can be found at http://dx.doi. org/10.1007/s11325-011-0544-7.

Q.-C. Lin $(\bowtie) \cdot$ X.-B. Zhang · G.-P. Chen · D.-Y. Huang •

H.-B. Din $\cdot$ A.-Z. Tang

Department of Respiratory Medicine, The First Affiliated Hospital of Fujian Medical University,

NO 20, Chazhong Road, Taijiang District,

Fuzhou, Fujian Province 350005, People's Republic of China

e-mail: chang4e@126.com 